\title{
Non-Coding RNAs in Diffuse Large B-Cell Lymphoma
}

This article was published in the following Dove Press journal:

OncoTargets and Therapy

\section{Yan Shi \\ Daihong Ding \\ Rongfeng Qu \\ Yan Tang \\ Shuhong Hao}

Department of Hematology and Oncology, The Second Hospital of jilin University, Changchun, Jilin, People's

Republic of China
Correspondence: Shuhong Hao

Ziqiang Street No. 218, Changchun, Jilin

| 3004 I, People's Republic of China

$\mathrm{Tel} / \mathrm{Fax}+860431$ 8II 36427

Email haoshuhong@jlu.edu.cn

\begin{abstract}
Diffuse large B-cell lymphoma (DLBCL) is the most common type of nonHodgkin lymphoma worldwide. The molecular mechanisms underlying DLBCL have not been fully elucidated, and approximately $40 \%$ of patients who undergo standard chemoimmunotherapy still present with primary refractory disease or relapse. Non-coding RNAs (ncRNAs), a group of biomolecules functioning at the RNA level, are increasingly recognized as vital components of molecular biology. With the development of RNA-sequencing (RNA-Seq) technology, accumulating evidence shows that ncRNAs are important mediators of diverse biological processes such as cell proliferation, differentiation, and apoptosis. They are also considered promising biomarkers and better candidates than proteins and genes for the early recognition of disease onset, as they are associated with relative stability, specificity, and reproducibility. In this review, we provide the first comprehensive description of the current knowledge regarding three groups of ncRNAs - microRNAs (miRNAs), circular RNAs (circRNAs), and long non-coding RNAs (lncRNAs) - focusing on their characteristics, molecular functions, as well as diagnostic and therapeutic potential in DLBCL. This review provides an exhaustive account for researchers to explore novel biomarkers for the diagnosis and prognosis of DLBCL and therapeutic targets.
\end{abstract}

Keywords: diffuse large B-cell lymphoma, microRNA, circRNA, long non-coding RNA

\section{Introduction}

Diffuse large B-cell lymphoma (DLBCL) is the most common type of non-Hodgkin lymphoma worldwide, accounting for approximately $30-40 \%$ of all cases in different geographical regions. ${ }^{1}$ Patients most often present with a heterogeneous group of tumors, characterized by a high degree of genetic abnormalities, different clinical features, responses to treatment, and prognoses. ${ }^{2}$ Although standard therapy for patients with DLBCL has been established, a proportion of patients still relapse despite standard chemoimmunotherapy treatment with rituximab, cyclophosphamide, doxorubicin hydrochloride, vincristine sulfate, and prednisone (R-CHOP). ${ }^{3}$ Allogeneic hematopoietic stem cell transplantation (allo-HSCT) and chimeric antigen receptor (CAR) $\mathrm{T}$ cell therapy for relapsed/refractory DLBCL patients have been unsuccessful in achieving durable remission. ${ }^{4,5}$ Hence, identifying novel biomarkers for diagnosis and prognosis and therapeutic targets for DLBCL are needed.

Non-coding RNAs (ncRNAs) are functional small RNA molecules that are not translated into proteins. ${ }^{6}$ RNA transcripts without protein-coding potential have been reported to represent more than $90 \%$ of the human genome. ${ }^{7}$ Based on their 
functions, these ncRNAs can be separated into housekeeping and regulatory transcripts. The regulatory ncRNAs, mainly including microRNAs (miRNAs), circular RNAs (circRNAs), and long non-coding RNAs (lncRNAs), extensively participate in the regulation of gene expression, associated biochemical pathways, and cellular functions. This regulation is necessary to maintain homeostasis, and its dysregulation is often associated with disease development. ${ }^{8}$ With the advent of novel highthroughput techniques, an increasing number of ncRNAs have been recognized to be involved in the pathogenesis of hematological malignancies, including leukemia, lymphoma, and multiple myeloma (MM). ${ }^{9}$ This review focuses on the roles of miRNAs, circRNAs, and lncRNAs in DLBCL and illustrates their diagnostic and prognostic potential for this disease.

\section{miRNAs}

miRNAs are short ncRNAs, approximately 22 nucleotides long, that negatively regulate the expression of their target genes at the transcriptional level by binding to the $3^{\prime}$ untranslated region ( $3^{\prime}$-UTR) within the target messenger RNA (mRNA).$^{10}$ miRNAs affect critical cell processes, such as proliferation, the cell cycle, and apoptosis. ${ }^{11}$ Growing evidence indicates that miRNAs have essential functions in malignant B-cell development. ${ }^{12-17}$ In addition to coding genes, some non-coding genes, especially miRNAs, are considered to be among the most critical targets for regulating DLBCL development. ${ }^{18}$

\section{Aberrant Expression of miRNAs in DLBCL}

Abnormal expression of miRNAs is common in B-cell neoplasms, including B-cell lymphoma. The expression of individual miRNAs and miRNA signatures can help identify specific cell differentiation stages, which is a powerful diagnostic and prognostic method. ${ }^{16}$ Jardin et al demonstrated distinct changes in the expression of stage-specific miRNAs in B-cell differentiation, from the naïve B-cell stage (upregulated: miR-181, miR-34a, and miR-223), through germinal center (GC) maturation (upregulated: miR-17-5p, miR-181b, miR-125b, and miR-155; downregulated: miR-223 and miR-150), to the final stage, leading to either memory B cells (upregulated: miR-223 and miR-181-b; downregulated: miR-17-5p) or plasma cells (downregulated: miR-181b, miR-17-5p, and miR-30). ${ }^{16}$ Interestingly, DLBCL shows the most heterogeneous miRNA profiles of all lymphoma types analyzed. ${ }^{17}$ Lim et al conducted the first in-depth sequencing analysis of the DLBCL miRNome (global miRNA expression levels). They noted that 63 and 39 miRNAs exhibited increased and decreased abundance, respectively, in DLBCL. ${ }^{19}$ miR-155 and miR-146a were significantly overexpressed in de novo DLBCL patients, and their expression was distinct from that in reactive hyperplasia lymphoid nodes. ${ }^{20}$ Besides, several studies have analyzed the association between miRNA expression and the clinicopathological features of patients with DLBCL. miR214 was found to be downregulated in DLBCL patients, and low miR-214 expression was positively associated with tumor size, clinical stage, and International Prognostic Index (IPI) score. ${ }^{21}$ High miR-155 expression was also significantly associated with adverse clinicopathological features, including activated B-cell (ABC)-type DLBCL, the presence of $\mathrm{B}$ symptoms, the involvement of extranodal sites, higher IPI, and Eastern Cooperative Oncology Group (ECOG) score. ${ }^{22,23}$

\section{Functions and Mechanisms of miRNAs in DLBCL}

Several studies have confirmed that miRNAs can affect important cellular processes, including proliferation, the cell cycle, and apoptosis in DLBCL. For example, as an oncogenic miRNA, miR-155 is reportedly overexpressed in DLBCL tissue compared to control tissue, and it increases cell proliferation and directly or indirectly enhances the G1/S phase transition. ${ }^{24}$ Similarly, Li et al showed that miR-155 downregulation inhibits lymphoma cell progression by arresting the cell cycle in the G0/G1 phase and promoting apoptosis. A subsequent tumor formation study in nude mice indicated that miR-155 downregulation delays the progress of tumor formation. ${ }^{25}$ Another study reported that miR-34a delivery induces apoptosis and suppresses the growth of DLBCL cells in vivo. ${ }^{26}$

The most common mechanism of action of miRNAs is binding to complementary sequences on the target mRNA to negatively regulate target genes at the translational and post-transcriptional level. Some miRNAs might play an oncogenic role by regulating the expression of target genes. In DLBCL, miR-155 is a topic of active investigation. The identified targets of miR155 include suppressor of cytokine signaling 3 (SOCS3), ${ }^{27} p 85 \alpha$ (PIK3R1), ${ }^{28} \mathrm{SH} 2$ domain-containing inositol-5-phosphatase (SHIPl) ${ }^{29}$ bone morphogenetic protein (BMP)-responsive transcriptional 
factor (SMAD5), ${ }^{30}$ PU.1, ${ }^{31}$ Wee1. ${ }^{32} \mathrm{Li}$ et al showed that miR-155 could enhance cell proliferation and inhibit apoptosis by targeting the downregulated SOCS3 expression to activate the Janus kinase (JAK)/signal transducer and activator of transcription 3 (STAT3) signaling pathway. ${ }^{27}$ Huang et al showed that miR-155 activates the phosphatidylinositol 3-kinase (PI3K)/protein kinase B (AKT) pathway by targeting $p 85 \alpha(P I K 3 R 1)$ and indirectly enhances the phosphorylation of AKT, critical for cellular transformation. ${ }^{28}$ Another study identified that oncogenic miR-155 targets $S H I P 1$ to promote tumor necrosis factor- $\alpha$ (TNF- $\alpha$ )-dependent growth of DLBCL. ${ }^{29}$ Further, the targeting of SMAD5 by miR-155 results in sustained phosphorylation of retinoblastoma protein $(\mathrm{RB})$ and decreased abundance of free E2F transcription factor 1 (E2F1), limiting $\mathrm{G} 0 / \mathrm{G} 1$ arrest. $^{30}$ miRNA-21, an oncogenic agent, is significantly overexpressed in DLBCL tissues; moreover, it might increase DLBCL cell viability and decrease their apoptosis via anti-apoptotic effects by upregulating B-cell lymphoma 2 (BCL-2) gene expression. ${ }^{33}$ This miRNA could downregulate phosphatase and tensin homolog deleted on chromosome ten $(P T E N)$ to inhibit DLBCL cell apoptosis. ${ }^{34}$ Likewise, Go et al demonstrated that miR-21 downregulates forkhead box protein $\mathrm{O} 1$ (FOXO1), a direct target of miR-21, in both direct and indirect manners, by binding to the 3 '-UTR of FOXO1 and activating the $\mathrm{PI} 3 \mathrm{~K} / \mathrm{AKT} / \mathrm{mammalian}$ target of rapamycin (mTOR) pathway to increase the cell proliferation in DLBCL. ${ }^{23}$ The upregulation of $\mathrm{miR}-125 \mathrm{a} / \mathrm{b}$ directly acts on TNF- $\alpha$-induced protein 3 (TNFAIP3) to promote the activation of the NF- $\kappa \mathrm{B}$ pathway, which is associated with aggressiveness in human DLBCL cell lines. ${ }^{35}$ Some studies support the contribution of miRNA let-7, particularly let-7b, to specific interactions with the PR domain zinc finger protein 1 (PRDM1) 3'-UTR and the downregulation of gene expression, thereby representing one of the mechanisms promoting tumorigenesis of DLCBL. ${ }^{36}$

Meanwhile, research on tumor suppressor miRNAs has yielded important results. The BCL6 gene is a protooncogene that is often expressed in DLBCL. Fan et al showed that miR-10a, which is reportedly downregulated in DLBCL, might inhibit proliferation and promote apoptosis by directly binding to the $3^{\prime}$-UTR of the BCL6 mRNA transcript. ${ }^{37}$ Moreover, BCL6 is a target of miR-187, with miR-187 indirectly promoting lymphoma cell apoptosis and enhancing multidrug (doxorubicin, bortezomib, and vincristine) sensitivity by targeting its $3^{\prime}-\mathrm{UTR}^{38} \mathrm{miR}-26 \mathrm{a}$, as a tumor suppressor, suppresses the proliferation and cell cycle progression of DLBCL cells by regulating $p 35$ expression and inhibiting cyclin-dependent kinase 5 (CDK5)/ STAT3 signaling. ${ }^{39}$ Another study reported that miR-27b suppressed proliferation and promoted apoptosis by directly targeting the mesenchymal-epithelial transition factor (MET) and repressing the oncogenic MET/PI3K/AKT pathway. ${ }^{40}$ Moreover, miR-101 downregulation significantly promoted cell proliferation and suppressed cell apoptosis by targeting lysine-specific histone demethylase $1 \mathrm{~A}(K D M 1 A){ }^{41}$ The overexpression of miR-214 significantly attenuates the malignant phenotype of DLBCL OCI-Ly3 cells in vitro and restricts tumor growth in a xenograft mouse model by targeting programmed death-ligand $1(P D-L 1) .^{21}$ At the posttranscriptional level, miR-224 was determined to regulate CD59 expression and influence cell proliferation, invasion, and apoptosis. $^{42}$ In addition, in ABC-type DLBCL cell lines, miR-181a overexpression could result in G0/G1 cell cycle arrest, increased apoptosis, and decreased invasion via the inhibition of caspase activation and recruitment domain 11 (CARD11). ${ }^{43}$

In addition to regulating the expression of target genes, other miRNA-related functions and mechanisms have been reported in DLBCL. Several single-nucleotide polymorphisms (SNPs) or mutations occurring in the miRNA gene region can affect miRNA properties and expression. Zhuang et al suggested that the miR-146a rs2910164 polymorphism can functionally affect the expression of miR146a, which might explain the risk and pathogenesis of DLBCL in a Chinese Han population. ${ }^{44} \mathrm{Li}$ et al pointed out that the miR-196a2 polymorphism might increase the risk of DLBCL by altering the expression of mature miR$196 \mathrm{a} 2{ }^{45}$ Indeed, several variants in miRNA genes or target sites have been shown to contribute to the development of DLBCL by affecting miRNA-mediated transcriptional regulatory functions. Kwanhian et al reported somatic mutations in miR-142 that might result in growth stimulation in DLBCL. ${ }^{46}$

\section{miRNAs Serve as Biomarkers in DLBCL Potential Biomarkers for Diagnosis}

There is ample evidence that a distinct miRNA signature characterizes DLBCL. For example, DLBCL cells were shown to have 10 - to 30 -fold higher miR-155 copy numbers than those in normal circulating $\mathrm{B}$ cells. ${ }^{47} \mathrm{Di}$ Lisio et al proposed a model of 128 miRNAs enabling the discrimination of various lymphoid malignancies, including DLBCL, Burkitt lymphoma (BL), follicular lymphoma (FL), marginal zone lymphoma (MZL), mantle cell 
lymphoma (MCL), and chronic lymphocytic leukemia (CLL). ${ }^{48}$ To discriminate between DLBCL and BL, a specific set of 19 miRNAs differentially expressed between the two lymphoma types was obtained. ${ }^{48}$ Similarly, Lenze et al analyzed the miRNA expression of $64 \mathrm{BL}$ and 86 DLBCL samples using analysis of variance, showing that 38 mature miRNAs may distinguish BL from DLBCL, ${ }^{49}$ and five of the described miRNAs (miR-155, miR-146a, miR-26a, miR-29b, and miR-34b) are in accordance with Di Lisio's data, among which miR-155 is the most significantly downregulated miRNA in BL. Gebauer et al concluded that the 10 miRNA signatures, which yielded independent biological characterizations of DLBCL and transformed nodal marginal zone lymphoma (NMZL), may be a valuable aid in discriminating between NMZL and DLBCL. ${ }^{50}$ Moreover, four miRNAs, including miR-330, miR17-5p, miR-106a, and miR-210, were found to discriminate DLBCL, FL, and lymph nodes (LNs) with an overall accuracy of $98 \% .{ }^{51}$ Regarding the differentiation between DLBCL and FL, one study identified that the expression levels of miR-20b, miR-26a, miR-92b, and miR-487b were lower in DLBCL than in FL. ${ }^{52}$ Fassina et al highlighted the miR-17-92 cluster as a useful tool to differentiate GC B-cell (GCB) DLBCL and high-grade FL. ${ }^{53}$ Yet another study showed that miR-4284 and miR4484 could serve as putative diagnostic biomarkers to help distinguish between DLBCL and reactive LN (RLN) hyperplasia. ${ }^{54}$

\section{Potential Biomarkers for Subtype Classification}

Abundant findings have confirmed specific miRNA signatures to distinguish the molecular subtypes of DLBCL. Lawrie et al showed that the expression levels of miR-21, miR-155, and miR-221 are 4.1-, 2.6-, and 1.5-fold higher in ABC- than in GCB-type cell lines, respectively. ${ }^{55}$ MontesMoreno et al determined that miR-331, miR-151, miR-28, and miR-454-3p were upregulated in GCB-type DLBCL, while the expression levels of miR-222, miR-144, miR451, and miR-221 were higher in ABC-type DLBCL. ${ }^{56}$ miR-21 expression levels in non-GCB-type DLBCL tissues are also higher than those in GCB-type DLBCL tissues. ${ }^{33}$ Different expression levels of miR-155 between DLBCL subtypes have been reported, with significantly higher levels in the non-GCB subtype ${ }^{22,32,57}$ and lower levels in the GCB subtype. ${ }^{55}$ The expression level of miR-146a was higher in ABC-type DLBCL patients than in GCB-type DLBCL patients, whereas miR-16 did not significantly differ between the two groups. ${ }^{20}$ Culpin et al suggested a nine-miRNA signature (miR-17-92 cluster, miR-29a, miR-106a, miR720, miR-1260, and miR-1280), all miRNAs of which are expressed at higher levels in ABC-like cell lines. However, this has not been verified at a clinical pathology level. ${ }^{52}$ Moreover, Fassina et al showed that miR-17-92 cluster miRNAs (miR-18b, miR-19b, miR-20a, miR-92, miR-93, and miR-106a) are significantly overexpressed in GCBtype DLBCL. ${ }^{53} \mathrm{Wu}$ et al showed that miR-320d is expressed at remarkably higher levels in DLBCLs of the GCB-type than in those of the ABC-type, suggesting that miR-320d might be useful a marker for subtype classification. ${ }^{58}$ Further, Zhu et al observed reduced miR-181a expression in ABCtype DLBCL cells, whereas miR-181b expression was similar between the ABC- and GCB-like DLBCL cell lines. $^{43}$

\section{Potential Biomarkers for Prognosis}

Although the IPI score is currently the most widely used predictive indicator for DLBCL, it has some limitations. ${ }^{59}$ Wu et al showed miR-155 overexpression to be associated with shorter progression-free survival (PFS), while a high IPI score indicated poor overall survival (OS). ${ }^{60} \mathrm{~A}$ higher expression level of this miRNA correlates with aggressive forms of DLBCL, ${ }^{57}$ and predicts lower event-free survival (EFS). ${ }^{22}$ The overexpression of miR-146a in DLBCL tends to be associated with more unfavorable prognoses and is reportedly associated with a lower complete remission (CR) rate, lower OS, and shorter PFS. ${ }^{20}$ Berglund et al demonstrated that high miR-200c expression was associated with a lower OS in DLBCL R-CHOP-treated patients. ${ }^{61}$ The univariate analysis by Alencar et al argued that miR-18a overexpression predicts a shorter OS, whereas increased expression of miR-222 and lower expression of miR-181a are associated with shorter PFS in DLBCL. ${ }^{62}$

In contrast, many other miRNAs tend to indicate more favorable prognoses. The high miR-21 expression in de novo DLBCL is associated with longer PFS and might serve as an independent predictive factor. ${ }^{55}$ DLBCL patients expressing a higher level of miR-224 have longer 5-year PFS and OS compared to those with lower miR-224 expression. ${ }^{63}$ Using univariate Cox regression, a significant correlation between high miR-34a expression and improved OS was observed by Marques et al. ${ }^{64}$ As a favorable biomarker, low expression of miR-27b was associated with poor OS of patients with DLBCL. ${ }^{40}$ Likewise, Zhong et al presented evidence that miR-146b-5p and miR-320d were expressed at lower levels in DLBCLs with poor prognosis by analyzing 106 primary 
nodal DLBCL samples from patients with the standard CHOP regimen. ${ }^{58}$ The lower expression of miR-197 was determined to be associated with frequent progression and reduced PFS in DLBCL after standard R-CHOP therapy, especially with the ABC subtype. ${ }^{65}$ Troppan et al indicated that miR-199a and miR-497 were upregulated in DLBCL compared to normal germinal cells. However, elevated miR199a and miR-497 levels are associated with improved survival in DLBCL patients, most likely increasing drug (doxorubicin, rituximab and, vincristine) sensitivity. ${ }^{66}$

\section{miRNAs Associated with Chemosensitivity and Chemoresistance in DLBCL}

miRNAs are increasingly being recognized as novel players in the evaluation of responses to chemotherapy in DLBCL. miR-21 has a vital role in regulating the chemosensitivity of DLBCL cells. Bai et al demonstrated that it impacts the PI3K/AKT signaling pathway by targeting PTEN, thus altering cellular sensitivity to the CHOP chemotherapeutic regimen. Furthermore, the knockdown of NF- $\kappa \mathrm{B}$ decreases miR-21 expression and increases the cytotoxic effects of the $\mathrm{CHOP}$ regimen in the CRL2631 cells of DLBCL. ${ }^{67}$ Marques et al observed that miR-34a is highly expressed in doxorubicin-sensitive cell lines and that the downregulation of FOXP1, a target of miR-34a, might increase the sensitivity of DLBCL cells to doxorubicin. ${ }^{68}$ Another study by Alencar et al revealed that miR-181a indirectly decreases O6methylguanine DNA methyltransferase (MGMT) protein expression, potentially contributing to better cyclophosphamide chemosensitivity. ${ }^{62}$ In vitro, miR-197 shows important functions in doxorubicin chemosensitivity by enhancing doxorubicin-induced apoptosis in SUDHL9 cells of ABC-type DLBCL, providing insights into effective therapeutic strategies. ${ }^{63}$ Besides, the overexpression of miR-370-3p, miR-381-3p, and miR-409-3p was found to be involved in DLBCL cell chemosensitivity in vitro because these miRNAs downregulated genes in the phosphatidylinositol, mitogen-activated protein kinase (MAPK), and B-cell antigen receptor (BCR) signaling pathways. $^{69}$

Conversely, abnormalities in diverse, complicated miRNA-related signaling pathways are intertwined with drug resistance. Kim et al reported that miR-124mediated restoration of glucocorticoid sensitivity is attributed to the inhibition of the AKT/mTOR/myeloid cell leukemia sequence 1 (MCL1) signaling pathway and induction of the glucocorticoid receptor by directly repressing phosphodiesterase 4B (PDE4B) expression and boosting cAMP concentrations in DLBCL. ${ }^{70}$ Yuan et al showed that DLBCL patients with sustained miR-125b and miR130a overexpression have a significantly higher probability of chemoresistance mediated by an abnormal NF- $\kappa \mathrm{B}$ signaling pathway than those with no or only one highly regulated miRNA. ${ }^{71}$ Sun et al indicated that histone deacetylase 6 (HDAC6) inhibits miR-148b by maintaining low acetylation of the histones $\mathrm{H} 3$ and $\mathrm{H} 4$ in the miR$148 \mathrm{~b}$ promoter, thus rescuing Ezrin protein expression and stimulating CHOP resistance in DLBCL. ${ }^{72}$ The study highlighted that a reduction or knockout of miR-155 affects vincristine resistance in vincristine-sensitive SUDHL-5 cells (GCB-type DLBCL cell lines). Furthermore, miR-155 functionally induces vincristine sensitivity through the cell cycle checkpoint Weel in DLBCL cells of the GCB subclass. ${ }^{32}$ Besides, ATP-binding cassette transporter-mediated multidrug resistance was reported in DLBCL. Go et al showed that miR-21 increases the expression and activity of multidrug-resistant protein 1 (MDR1), encoded by ATP-binding cassette subfamily $\mathrm{B}$ member $1(A B C B 1)$, to reduce doxorubicin resistance in DLBCL cells by downregulating the activity of the FOXO1/Bim pathway. $^{23}$ Nevertheless, exosomal miRNAs have been shown to participate in chemotherapy resistance. Feng et al demonstrated that the expression levels of exosomal miR-99a-5p and miR-125b-5p are significantly higher in multidrug-resistant DLBCL SU-DHL $-2 / \mathrm{R}$ cells than in SU-DHL-2 cells. Further, the knockdown of miR-99a-5p and miR-125b-5p was found to enhance chemotherapeutic efficacy, resulting in better PFS. $^{73}$

\section{miRNAs Associated with Virus-Related DLBCL}

The association between viral infection and DLBCL has been confirmed in numerous studies. Epstein-Barr virus (EBV) infection profoundly influences the cellular miRNA profile in DLBCL. Nine miRNAs (miR-424, miR-223, miR-199a-3p, miR-199a-5p, miR-27b, miR-378, miR26b, miR-23a, and miR-23b) and seven miRNAs (miR155, miR-20b, miR-221, miR-151-3p, miR-222, miR-29b/ c, and miR-106a) were found to be upregulated and downregulated, respectively, in EBV-positive DLBCL. ${ }^{74} \mathrm{miR}$ 155 is considered to be the most studied molecular marker 
in EBV-positive DLBCL. The expression of miR-155 was observed to be higher in EBV-positive DLBCL according to an in vitro study wherein the EBV-encoded protein, latent membrane protein 1 (LMP1) induced the expression of B-cell integration cluster (BIC), a precursor form of miR-155, in B-lymphoma cells. ${ }^{75}$ Likewise, Wood et al showed that the EBV transcription factor, EBV nuclear antigens-2 (EBNA-2), upregulates miR-155 expression by activating an enhancer upstream from the miR-155 host gene $(m i R-155 H G)$, from which miR-155 is derived. ${ }^{76}$ Further, EBV-positive patients show higher serum miR155 levels than those of EBV-negative patients. ${ }^{77}$ There are only a few other reports of miRNAs in EBV-positive DLBCL. In one study, miR-424 was the most strongly upregulated miRNA by EBV-infection in primary DLBCL tissue and the cell lines studied; this miRNA upregulated $\beta$-catenin protein to promote tumor development by inhibiting tumor suppressor seven in absentia homolog 1 (SIAH1) expression. ${ }^{74}$ In elderly patients, miR-146b and miR-222 show high specificity for identifying EBV-positive DLBCL and are considered potential biomarkers and therapeutic targets. ${ }^{78}$

DLBCL is the most common AIDS-related lymphoma (ARL), which occurs at an advanced stage and with B symptoms and involves extranodal tissue, mainly in severely immunosuppressed patients. ${ }^{79}$ miRNAs play pivot in the development and progression of human immunodeficiency virus (HIV)-associated DLBCL. Thapa et al showed that miRNAs from the miR-17-92 paralog clusters are overexpressed in AIDS-related DLBCL cases, revealing an oncogenic role for these miRNAs owing to their inhibition of $\mathrm{p} 21 .^{80}$ Subsequent studies have supported the use of circulating miR-21, miR-122, and miR-223 levels to discriminate between HIV-infected and uninfected individuals, and higher serum levels of miR-222 can also serve as a diagnostic marker for earlier detection of HIVinfected DLBCL. ${ }^{81}$

Epidemiological studies have shown an increased risk of developing B-cell lymphomas in patients with chronic hepatitis $\mathrm{C}$ virus (HCV) infection. ${ }^{82}$ Augello et al detected 6 and 14 miRNAs that were upregulated and downregulated, respectively, in $\mathrm{HCV}$-associated DLBCL with respect to non-infected ones. Importantly, these researchers found that decreased expression of miR-138-5p and increased expression of miR-147a, miR-147b, and miR511-5p were poor prognostic factors for $\mathrm{HCV}$-positive DLBCL patients. $^{83}$

\section{circRNAs}

circRNAs, a novel type of ncRNA with a covalently closed loop structure generated by head-to-tail splicing, have attracted great research interest lately. ${ }^{84}$ There are four categories of circRNAs, namely exonic circRNAs, circular intronic RNA, exon-intron circRNAs, and intergenic circRNAs. ${ }^{85}$ Based on the relevant literature, we can highlight several remarkable characteristics of circRNAs as follows. (1) They exist in high abundance; Jeck et al reported circRNAs to be considerably more abundant ( $>10$-fold) than the corresponding linear mRNAs. ${ }^{86}$ (2) They have high stability; the structures lack free ends, which provides high resistance to RNA exonuclease or RNase R activity, conferring higher stability than linear RNAs. ${ }^{87,88}$ Some studies have shown that circRNA transcript half-lives exceed 48 h. ${ }^{86}$ (3) They are highly conserved; circRNAs show an ancient, evolutionarily conserved feature in different species. ${ }^{86,89}$ With the combination of highthroughput sequencing and new computational algorithms, thousands of circRNAs have now been revealed in species spanning from humans to archaea. ${ }^{86,87,89}$ (4) They exhibit specific expression; circRNAs often exhibit tissue-/developmental stage-specific expression. For example, Nicolet et al provided the first comprehensive analysis of circRNA expression in human hematopoietic cells, suggesting that their expression increases upon maturation..$^{90}$ circRNA functions depend on subcellular localization. Cytoplasmic circRNAs can function as miRNA sponges, binding to proteins and even translating proteins, whereas nuclear circRNAs might participate in the regulation of gene expression by binding to proteins. ${ }^{91}$ Extensive studies have confirmed that circRNAs can function as competitive endogenous RNA (ceRNA), reducing their inhibitory effects on target genes by efficiently sponging miRNAs. ${ }^{92}$

circRNAs are known to be related to the occurrence, development, and progression of human diseases, especially cancer. ${ }^{93}$ circRNAs might function as oncogenes or tumor suppressors to alter tumor cell proliferation, apoptosis, invasion, and migration. ${ }^{94}$ Emerging evidence indicates that circRNAs participate in the oncogenesis of several carcinomas, including breast cancer, ${ }^{95}$ lung cancer, ${ }^{96}$ and colorectal cancer. ${ }^{97}$ However, only a few published studies show that circRNAs participate in the etiology of DLBCL.

$\mathrm{Hu}$ et al identified a novel and highly stable DLBCLrelated circRNA, circ-APC (hsa_circ_0127621), which was reportedly downregulated in DLBCL tissues, cell lines, and plasma, as evidenced by microarray 
analysis. ${ }^{91}$ Their study reported that the inhibitory effects of circ-APC on DLBCL cell proliferation depend on its ability to upregulate adenomatous polyposis coli ( $A P C$ ). Upregulated $A P C$ dampens the canonical $\mathrm{Wnt} / \beta$-catenin signaling pathway to retard DLBCL growth by reducing the nuclear accumulation of $\beta$-catenin. Further evidence identified that nuclear circ-APC binds to the $A P C$ promoter and recruits the DNA demethylase Ten-eleven translocation 1 (TET1), thereby transcriptionally upregulating $A P C$. Cytoplasmic circ-APC, acting as a sponge for miR-888, increases $A P C$ expression by sponging and inhibiting miR-888, thus regulating the $\mathrm{Wnt} / \beta$-catenin signaling pathway and resulting in the proliferation of DLBCL cells. Notably, the OS is shorter for patients with lower circ-APC levels in DLBCL tissues, and circAPC expression might serve as an independent prognostic factor for DLBCL patients. Therefore, circ-APC is a novel proliferation inhibitor, and restoring circ-APC expression might be a promising therapeutic approach for DLBCL patients.

Dahl et al applied a new method for the accurate quantification of circRNAs, using NanoString technology with different B-cell malignancies, including DLBCL, BL, MCL, and MM. ${ }^{98}$ They elucidated the expression of 52 circRNA candidates, mainly focusing on circRNAs previously implicated in other cancers and those produced from host genes involved in lymphomagenesis. The results showed that circRNA expression profiles could help distinguish different B-cell malignancies. They also found a novel circRNA, derived from the Ikaros family zinc finger 1 (IKZF3) gene, which was determined to be highly expressed in MM and DLBCL cell lines.

\section{IncRNAs}

lncRNAs are a class of ncRNAs over 200 nucleotides long, which lack or have little protein-coding capacity. ${ }^{99}$ Based on their genomic location, IncRNAs are classified into sense lncRNAs, antisense lncRNAs, bidirectional lncRNAs, and intron and intergenic lncRNAs. ${ }^{100}$ The aberrant expression of lncRNAs is strongly associated with tumorigenesis, tumor progression, and metastasis, highlighting their clinical applications as diagnostic and prognostic biomarkers, as well as therapeutic targets in different cancer types.

\section{Expression of IncRNAs in DLBCL}

lncRNAs, which are expressed in highly tissue- and cell typespecific manners, are functionally critical for the development of human diseases. Lymphoid differentiation-related
IncRNAs have been explored in recent years. ${ }^{101}$ Tayari et al showed the dynamic regulation of lncRNA expression during $B$ cell transition from naïve B cells to GC-B cells, resulting in memory B cells. ${ }^{102}$ One study examined RNA-Seq data sets of DLBCL and identified 2632 novel, multi-exonic candidate lncRNAs expressed in more than one DLBCL tumor, most of which are not expressed in normal B cells. ${ }^{103}$ By applying microarray technology, Gao et al revealed 1648 significantly upregulated lncRNAs and 2671 significantly downregulated lncRNAs in two different GCB-type DLBCL cell lines (OCIly1 and OCI-ly19) compared to the levels in normal B lymphocytes. ${ }^{104}$ Using IncRNA chip array assays, another study reported that 1053 lncRNAs were remarkably differentially expressed in DLBCL cell lines compared with normal B cells, and 416 and 637 of these lncRNAs were upregulated and downregulated, respectively. ${ }^{105}$ In an in silico study, among 189 candidate lncRNAs, growth arrestspecific 5 (GAS5), miR-17-92a-1 cluster host gene (MIR17HG), highly upregulated in liver cancer (HULC), and prostate cancer antigen 3 (PCA3) were found to be highly altered in DLBCL patients, and abnormal expression of GAS5 was most commonly detected. ${ }^{106}$

\section{Functions and Mechanisms of IncRNAs in DLBCL}

The importance of lncRNAs in a variety of biological functions, including cell proliferation, differentiation, and apoptosis, has been established. ${ }^{107}$ These lncRNAs are reported to be extensively involved in the biological mechanisms of DLBCL by "sponging" intracellular molecules to indirectly block their biological functions with downstream factors. For instance, Wang et al showed that the lncRNA metastasisassociated lung adenocarcinoma transcript 1 (MALAT-1) is upregulated in DLBCL and sponges miR-195 to enhance DLBCL cell proliferation, migration, and resistance to CD8 $+\mathrm{T}$ cell cytotoxicity by inducing the expression of $P D-L 1$. Besides, MALAT-1 was also found to promote epithelialmesenchymal transition (EMT)-like processes by activating the Ras/extracellular signal-regulated kinase (ERK) signaling pathway through the miR-195/PD-L1 axis. ${ }^{108}$ The lncRNA small nucleolar RNA host gene 14 (SNHG14) can act as a ceRNA sponge of miR-5590-3p to upregulate the downstream protein zinc finger E-box binding homeobox 1 (ZEB1), which transcriptionally activates SNHG14 and PDL1 to promote immune evasion of DLBCL cells. ${ }^{109}$ Similarly, lncRNA SNHG16 can also promote proliferation and cell cycle progression by directly interacting with miR- 
Table I miRNAs in Diffuse Large B Cell Lymphoma

\begin{tabular}{|c|c|c|c|c|c|}
\hline miRNAs & $\begin{array}{l}\text { Altered } \\
\text { Expression }\end{array}$ & Targets & Pathways & Function & Reference \\
\hline miR-IOa & Downregulated & BCL-6 & - & $\begin{array}{l}\text { Inhibit cell proliferation and promote } \\
\text { apoptosis }\end{array}$ & 37 \\
\hline \multirow[t]{4}{*}{ miR-2I } & \multirow[t]{4}{*}{ Upregulated } & BCL-2 & - & Promote proliferation and inhibit apoptosis & 33 \\
\hline & & PTEN & - & Inhibit apoptosis & 34 \\
\hline & & FOXOI & $\begin{array}{l}\mathrm{PI} 3 \mathrm{~K} / \mathrm{AKT} / \mathrm{mTOR} \\
\text { signaling pathway }\end{array}$ & $\begin{array}{l}\text { Increase proliferation, drug resistance and } \\
\text { inhibit apoptosis }\end{array}$ & 23 \\
\hline & & PTEN & $\begin{array}{l}\text { PI3K/AKT signaling } \\
\text { pathway }\end{array}$ & $\begin{array}{l}\text { Increase chemoresistance to the CHOP } \\
\text { regimen }\end{array}$ & 67 \\
\hline $\operatorname{miR}-26 a$ & Downregulated & p35 & $\begin{array}{l}\text { CDK5/STAT3 signaling } \\
\text { pathway }\end{array}$ & Inhibit proliferation and cell cycle progression & 39 \\
\hline $\operatorname{miR}-27 b$ & Downregulated & MET & $\begin{array}{l}\text { PI3K/AKT signaling } \\
\text { pathway }\end{array}$ & $\begin{array}{l}\text { Inhibit cell viability, proliferation and promote } \\
\text { apoptosis }\end{array}$ & 40 \\
\hline \multirow[t]{2}{*}{ miR-34a } & \multirow[t]{2}{*}{ Downregulated } & FOXPI & - & Increase chemosensitivity to doxorubicin & 64 \\
\hline & & - & - & $\begin{array}{l}\text { Inhibit cell proliferation and promote } \\
\text { apoptosis }\end{array}$ & 26 \\
\hline miR-I0I & Downregulated & KDMIA & - & $\begin{array}{l}\text { Inhibit cell proliferation and promote } \\
\text { apoptosis }\end{array}$ & 41 \\
\hline miR-I 24 & - & PDE4B & $\begin{array}{l}\text { AKT/mTOR/MCLI } \\
\text { signaling pathway }\end{array}$ & Increase chemosensitivity of glucocorticoid & 70 \\
\hline $\mathrm{miR}-125 \mathrm{a} / \mathrm{b}$ & - & TNFAIP3 & NF- $\kappa B$ signaling pathway & Increase aggressiveness & 35 \\
\hline \multirow[t]{6}{*}{ miR-I55 } & \multirow[t]{6}{*}{ Upregulated } & TGFBR2 & - & $\begin{array}{l}\text { Promote proliferation, cell cycle progression } \\
\text { and inhibit apoptosis }\end{array}$ & 25 \\
\hline & & - & - & $\begin{array}{l}\text { Promote cell proliferation and cell cycle } \\
\text { progression }\end{array}$ & 24 \\
\hline & & SOCS3 & $\begin{array}{l}\text { JAK/STATsignaling } \\
\text { pathway }\end{array}$ & Promote proliferation and inhibit apoptosis & 27 \\
\hline & & $\mathrm{p} 85 \alpha$ & $\begin{array}{l}\text { PI3K/AKT signaling } \\
\text { pathway }\end{array}$ & $\begin{array}{l}\text { Promote proliferation, cellular transformation } \\
\text { and inhibit apoptosis }\end{array}$ & 28 \\
\hline & & SMAD5 & TGF- $\beta$ signaling pathway & Promote cell cycle progression & 30 \\
\hline & & SHIPI & - & Promote tumor growth & 29 \\
\hline \multirow[t]{2}{*}{ miR- $|8| \mathrm{a}$} & \multirow[t]{2}{*}{-} & CARDII & - & $\begin{array}{l}\text { Inhibit invasion, cell cycle progression and } \\
\text { promote apoptosis }\end{array}$ & 43 \\
\hline & & MGMT & - & Increase cyclophosphamide chemosensitivity & 62 \\
\hline miR-I87 & Downregulated & BCL-6 & - & $\begin{array}{l}\text { Promote apoptosis and increase } \\
\text { chemotherapy sensitivity }\end{array}$ & 38 \\
\hline $\begin{array}{l}\operatorname{miR}-199 a \\
\operatorname{miR}-497\end{array}$ & Upregulated & - & - & Increase chemosensitivity & 66 \\
\hline $\operatorname{miR}-2 \mid 4$ & Downregulated & PD-LI & - & Inhibit tumor growth & 21 \\
\hline
\end{tabular}

(Continued) 
Table I (Continued).

\begin{tabular}{|l|l|l|l|l|l|}
\hline miRNAs & $\begin{array}{l}\text { Altered } \\
\text { Expression }\end{array}$ & Targets & Pathways & Function & Reference \\
\hline miR-224 & Downregulated & CD59 & - & $\begin{array}{l}\text { Inhibit proliferation, invasion and promote } \\
\text { apoptosis }\end{array}$ & 42 \\
\hline $\begin{array}{l}\text { miR-146b-5p } \\
\text { miR-320d }\end{array}$ & Downregulated & - & - & Inhibit cell proliferation & 58 \\
\hline $\begin{array}{l}\text { miR-370-3p miR-38I-3p } \\
\text { miR-409-3p }\end{array}$ & Downregulated & - & $\begin{array}{l}\text { MAPK/BCR signaling } \\
\text { pathway }\end{array}$ & $\begin{array}{l}\text { Increase sensitivity to rituximab and } \\
\text { doxorubicin }\end{array}$ & 69 \\
\hline let-7b & Upregulated & PRDMI & - & Promote lymphomagenesis & 36 \\
\hline
\end{tabular}

Abbreviation: TGFBR2, transforming growth factor beta receptor 2 .

497-5p and inversely increasing the abundance of the downstream proto-oncogene proviral integration site for Moloney murine leukemia virus 1 (PIMI) in DLBCL cells. ${ }^{110}$ As another member of the same gene family, SNHG12 was recently reported to boost DLCBL tumorigenesis by sponging miR-195. ${ }^{111}$

lncRNAs might interfere with the cell cycle and promote the occurrence and development of DLBCL. Studies have shown that the lncRNA nuclear enriched abundant transcript 1_1 (NEAT1_1) is highly expressed in tumor cells, while its knockdown results in growth inhibition, cell cycle arrest, and apoptosis induction. ${ }^{112}$ The lncRNA leukemia-associated noncoding IGF1R activator RNA 1 (LUNAR1) knockdown has been found to significantly repress DLBCL cell proliferation by regulating its functional downstream targets, such as $E 2 F 1$, cyclin $D 1$, and $p 21$, to alter cell cycle progression. ${ }^{113}$ Peng et al demonstrated that IncRNA HULC knockdown might arrest cell proliferation and induce apoptosis by downregulating the expression of cyclin D1 and Bcl-2 proteins in DLBCL cells. ${ }^{114}$ Their study further showed that lncRNA long intergenic noncoding RNA-p21 (lincRNA-p21) could inhibit cell proliferation and induce cell cycle arrest by functionally modulating downstream $p 21$, cyclin D1, and CDK4 expression. ${ }^{115}$ In addition, as a tumor suppressor gene, lncRNA PANDA inhibits cell proliferation and induces $\mathrm{G} 0 / \mathrm{G} 1$ cell cycle arrest by silencing the MAPK/ERK signaling pathway in DLBCL cells. ${ }^{116}$ Another study showed that knocking down the expression of lncRNA HOTAIR inhibits cell proliferation, arrests the cell cycle in the G2/M phase, and induces cell apoptosis in vitro, partly through the PI3K/AKT/NF-kB pathway. ${ }^{117}$

The Wnt/ $\beta$-catenin signaling pathway is increasingly being implicated in lncRNA-mediated DLBCL development. Zhao et al found that the lncRNA SMAD5 antisense RNA 1 (SMAD5-AS1) can sponge miR-135b-5p to inhibit
DLBCL development via the classical $\mathrm{Wnt} / \beta$-catenin pathway. ${ }^{118}$ The lncRNA functional intergenic repeating RNA element (FIRRE) functions as an oncogene and activates the $\mathrm{Wnt} / \beta$-catenin signaling pathway to facilitate DLBCL cell proliferation and reduce cell apoptosis by translocating $\beta$-catenin into the nucleus. ${ }^{119}$ Forkhead box M1 (FOXM1), one of the likely transcription factors of the IncRNA olfactory receptor family 3 subfamily A member 4 (OR3A4), positively upregulated the expression of OR3A4 to enhance the occurrence of DLBCL via the $\mathrm{Wnt} / \beta$-catenin signaling pathway at the transcriptional level. $^{120}$

\section{IncRNAs as Biomarkers in DLBCL Potential Biomarkers for Diagnosis and Subtype Classification}

Mounting studies have analyzed the expression of IncRNAs by comparing DLBCL patients and healthy subjects. For instance, the lncRNAs PEG10 and LUNAR1 were upregulated in DLBCL patients, ${ }^{113,121}$ whereas PANDA was significantly downregulated. ${ }^{116}$ The area under the curve (AUC) of PEG10, PANDA, and LUNAR1 reached $0.8228,0.760$, and 0.9420 , respectively, indicating that these three lncRNAs could be diagnostic markers for distinguishing DLBCL patients from healthy individuals. ${ }^{113,116,121}$ Another study showed that the expression of five lncRNAs could help distinguish DLBCL with RLN. Among these differentially expressed IncRNAs, ENST00000424690, ENST00000425358, and NR_026892 were upregulated, and ENST00000464929 and ENST00000475089 were downregulated in DLBCL compared to RLN. ${ }^{104}$ Moreover, Deng et al demonstrated that NEAT1_1 could serve as a useful diagnostic tool to differentiate between DLBCL and lymphadenitis. ${ }^{112}$ 
Table 2 IncRNAs in Diffuse Large B Cell Lymphoma

\begin{tabular}{|c|c|c|c|c|c|}
\hline IncRNAs & $\begin{array}{l}\text { Altered } \\
\text { Expression }\end{array}$ & Targets & Pathways & Function & Reference \\
\hline MALAT-I & Upregulated & miR-195 & $\begin{array}{l}\text { Ras/ERK } \\
\text { signaling } \\
\text { pathway }\end{array}$ & $\begin{array}{l}\text { Increase proliferation, migration and immune escape, } \\
\text { promote EMT-like process and inhibit apoptosis by } \\
\text { regulation of PD-LI }\end{array}$ & 108 \\
\hline SNHGI 2 & Upregulated & miR-195 & - & Accelerate tumorigenesis of DLCBL & 111 \\
\hline SNHGI4 & Upregulated & $\begin{array}{l}\text { miR- } \\
5590-3 p\end{array}$ & - & $\begin{array}{l}\text { Promote cell proliferation, migration, immune evasion } \\
\text { and EMT-like processes }\end{array}$ & 109 \\
\hline SNHGI6 & Upregulated & $\begin{array}{l}\text { miR- } \\
497-5 p\end{array}$ & - & Promote cell proliferation and cell cycle progression & 110 \\
\hline NEATI_I & Upregulated & - & - & Promote cell viability and migration & 112 \\
\hline LUNARI & Upregulated & - & - & $\begin{array}{l}\text { Promote cell proliferation by regulating E2FI, cyclin DI } \\
\text { and } \mathrm{p} 2 \mathrm{I} \text { expression }\end{array}$ & 113 \\
\hline HULC & Upregulated & - & - & $\begin{array}{l}\text { Promote cell proliferation via regulating cyclin DI and } \\
\text { Bcl-2 }\end{array}$ & 114 \\
\hline HOTAIR & Upregulated & - & $\begin{array}{l}\mathrm{PI} 3 \mathrm{~K} / \mathrm{AKT} / \mathrm{NF}- \\
\text { KB signaling } \\
\text { pathway }\end{array}$ & Promote cell proliferation and cell cycle progression & 117 \\
\hline FIRRE & Upregulated & - & $\begin{array}{l}\text { Wnt/ } \beta \text {-catenin } \\
\text { signaling } \\
\text { pathway }\end{array}$ & $\begin{array}{l}\text { Facilitate DLBCL cell growth via modulation of the } \\
\text { nuclear translocation of } \beta \text {-catenin. }\end{array}$ & 119 \\
\hline OR3A4 & Upregulated & - & $\begin{array}{l}\text { Wnt/ } \beta \text {-catenin } \\
\text { signaling } \\
\text { pathway }\end{array}$ & Promote cell proliferation & 120 \\
\hline PEGIO & Upregulated & - & - & Promote cell proliferation and inhibit apoptosis & 121 \\
\hline LincRNA-p2I & Downregulated & - & - & $\begin{array}{l}\text { Inhibit cell proliferation and cycle progression via } \\
\text { regulating cyclin DI, CDK4 and p2I expression }\end{array}$ & 115 \\
\hline PANDA & Downregulated & - & $\begin{array}{l}\text { MAPK/ERK } \\
\text { signaling } \\
\text { pathway }\end{array}$ & Inhibit cell proliferation and accelerate cell cycle arrest & 116 \\
\hline SMAD5-ASI & Downregulated & $\begin{array}{l}\text { miR- } \\
135 b-5 p\end{array}$ & $\begin{array}{l}\text { Wnt/ } \beta \text {-catenin } \\
\text { signaling } \\
\text { pathway }\end{array}$ & $\begin{array}{l}\text { Regulate the expression of APC through binding to miR- } \\
\text { I35b-5p to inhibit cells proliferation }\end{array}$ & 118 \\
\hline NONHSAG026900 & Downregulated & - & - & Inhibit cell cycle activity to limit tumor growth & 123 \\
\hline SubSigLnc- 17 & $\begin{array}{l}\text { Upregulated: } 6 \\
\text { Downregulated:II }\end{array}$ & - & - & Discriminate $G C B$ and $A B C$ subtypes with high accuracy & 122 \\
\hline
\end{tabular}

Several studies have reported the connection between IncRNA expression patterns and subtype classification. A panel of 17 lncRNA biomarkers (ENTPD1-AS1, SACSAS1, SH3BP5-AS1, RP11-101C11.1, AC009892.10, RP168D18.4, MIR600HG, RP11-278 J6.4, RP11-203B7.2, CSMD2-AS1, CTC-467 M3.1, RP4-788P17.1, RP11-553
L6.5, CRNDE, RP11-519G16.3, RP11-21 L19.1 and MMEAS1) was integrated to form a lncRNA-based molecular signature (termed SubSigLnc-17), which could discriminate GCB from $\mathrm{ABC}$ subtypes, with high accuracy. ${ }^{122}$ Further, Zhao et al indicated that patients with the GCB subtype had significantly higher values of the IncRNA NONHSAG026900 than those 
with the non-GCB subtype, suggesting the diagnostic potential of NONHSAG026900. ${ }^{123}$ However, relevant studies related to subtype classification remain limited, and the available data are not sufficient for conclusively demonstrating that a single lncRNA can be used in clinical practice as a biomarker.

\section{Potential Biomarkers for Prognosis}

Numerous studies have shown that altered levels of lncRNAs are also closely associated with OS and appear to be powerful predictors of prognosis in DLBCL. Sun et al suggested that a six-lncRNA signature (SACS-AS1, MME-AS1, CSMD2AS1, RP11-360F5.1, RP11-25K19.1, and CTC-467M3.1) could provide additional prognostic information to improve survival prediction for DLBCL at the molecular level beyond the conventional IPI system. ${ }^{124}$ Patients with NONHSAG026900 overexpression were found to have longer 5-year OS or PFS than those from the low-expression group. As a favorable biomarker associated with DLBCL prognosis of patients, NONHSAG026900 could also improve the predictive power of IPI as an independent factor. ${ }^{123}$ Peng et al showed that HULC could represent a novel indicator of poor prognosis and be an independent factor to forecast the OS and PFS of DLBCL, ${ }^{114}$ whereas in a different study, the same authors showed PEG10 to only serve as an independent predictor of poor OS based on multivariate analysis. ${ }^{121}$ Increased expression of NEAT1_1 and FIEER and decreased PANDA expression are closely correlated with poorer clinical outcomes and OS in DLBCL patients. ${ }^{112,116,119}$ The results from a study by Yan et al revealed that DLBCL patients expressing higher levels of HOTAIR have a poorer prognosis. ${ }^{117}$ Besides, patients expressing high levels of lincRNA-p21 tend to have more favorable prognoses than their low-expression counterparts, $^{105}$ whereas LUNAR1 overexpression and OR3A4 overexpression were found to be unfavorable prognostic predictors for DLBCL. ${ }^{113,120}$

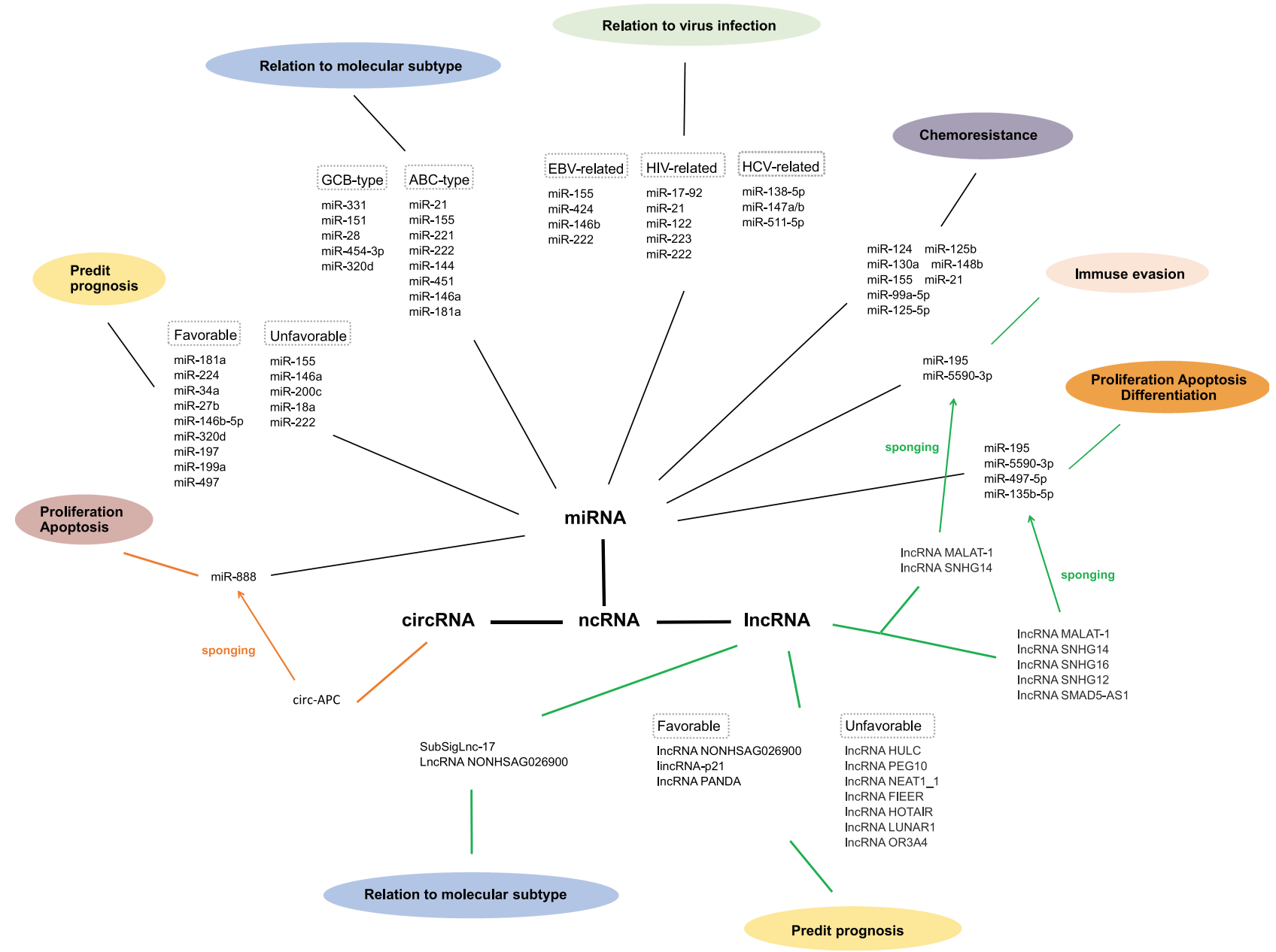

Figure I The connections of three groups of ncRNAs involved in diffuse large $B$ cell lymphoma.

Abbreviations: ncRNA, non-coding RNA; miRNA, microRNA; circRNA, circular RNA; IncRNA, long non-coding RNA; GCB, germinal center B-cell; ABC, activated B-cell; EBV, Epstein-Barr virus; HIV, human immunodeficiency virus; $\mathrm{HCV}$, hepatitis $\mathrm{C}$ virus. 


\section{Conclusion}

Abundant evidence suggests the functional role and therapeutic potential of ncRNAs in DLBCL, providing novel insights into the molecular mechanisms of DLBCL and opening clinical avenues toward the development of effective therapies. In this review, we discussed miRNAs, circRNAs, lncRNAs, and their involvement in the subtypes, pathogenesis, chemosensitivity, chemoresistance, and prognosis of DLBCL, as well as interactions with viral infections. The major roles of DLBCL-related miRNAs and lncRNAs are summarized in Tables 1 and 2 , respectively. The connections of these three groups of ncRNAs involved in DLBCL is shown in Figure 1. miRNAs are the most extensively studied ncRNAs in DLBCL. Some recent studies have focused on miRNAtargeted therapies, with rewarding treatment outcomes, whereas more research has been dedicated to investigating the therapeutic potential of the highly cell- and tissuespecific lncRNAs and circRNAs in DLBCL. However, there is limited literature on the connections among these three ncRNAs concerning complex regulatory mechanisms. The advent of the post-genomics era calls for discovering additional DLBCL-related ncRNAs to decipher the exact underlying mechanisms. Nevertheless, we intend to explore related aspects and investigate the interactions among the regulatory networks of miRNAs, circRNAs, and lncRNAs in the foreseeable future.

\section{Funding}

This work was supported by grants from the Education Department of Jilin Province, P.R.C. (No. JJKH20 190059KJ), the Science and Technology Department of Jilin Province, P.R.C. (No. 20190201050JC), the Science and Technology Department of Jilin Province, P.R.C. (No. 20200201543JC).

\section{Disclosure}

The authors declare no competing financial and/or nonfinancial interests in relation to the work described.

\section{References}

1. Li S, Young KH, Medeiros LJ. Diffuse large B-cell lymphoma. Pathology. 2018;50(1):74-87. doi:10.1016/j.pathol.2017.09.006

2. Lossos IS, Morgensztern D. Prognostic biomarkers in diffuse large B-cell lymphoma. J Clin Oncol. 2006;24(6):995-1007. doi:10.1200/ JCO.2005.02.4786

3. Friedberg JW. Relapsed/refractory diffuse large B-cell lymphom. Hematology. 2011;2011:4985-5005. doi:10.1182/asheducation-2011. 1.498
4. Jacobs R, Ghosh N. Conditioning prior to allogeneic hematopoietic stem cell transplants for relapsed/refractory diffuse large B-cell lymphoma-is more actually less? Biol Blood Marrow Transplant. 2020;26(4):e75-e76. doi:10.1016/j.bbmt.2020.02.002

5. Schuster SJ, Bishop MR, Tam CS, et al. Tisagenlecleucel in adult relapsed or refractory diffuse large B-Cell lymphoma. $N$ Engl $J$ Med. 2019;380(1):45-56. doi:10.1056/NEJMoa1804980

6. Llave C, Xie Z, Kasschau KD, Carrington JC. Cleavage of scarecrow-like mRNA targets directed by a class of arabidopsis miRNA. Science. 2002;297(5589):2053-2056. doi:10.1126/ science. 1076311

7. ENCODE Project Consortium. An integrated encyclopedia of DNA elements in the human genome. Nature. 2012;489 (7414):57-74. doi:10.1038/nature11247.

8. Esteller M. Non-coding RNAs in human disease. Nat Rev Genet. 2011;12(12):861-874. doi:10.1038/nrg3074

9. Ghafouri-Fard S, Esmaeili M, Taheri M. Expression of non-coding RNAs in hematological malignancies. Eur $J$ Pharmacol. 2020;875:172976. doi:10.1016/j.ejphar.2020.172976

10. Bartel DP. MicroRNAs: genomics, biogenesis, mechanism, and function. Cell. 2004;116(2):281-297. doi:10.1016/s00928674(04)00045-5

11. Bracken CP, Scott HS, Goodall GJ. A network-biology perspective of microRNA function and dysfunction in cancer. Nat Rev Genet. 2016;17(12):719-732. doi:10.1038/nrg.2016.134

12. Getaneh Z, Asrie F, Melku M. MicroRNA profiles in B-cell non-Hodgkin lymphoma. EJIFCC. 2019;30(2):195-214.

13. Zheng B, Xi Z, Liu R, et al. The function of MicroRNAs in B-Cell development, lymphoma, and their potential in clinical practice. Front Immunol. 2018;9:936. doi:10.3389/fimmu.2018. 00936

14. Musilova K, Mraz M. MicroRNAs in B-cell lymphomas: how a complex biology gets more complex. Leukemia. 2015;29 (5):1004-1017. doi:10.1038/leu.2014.351

15. Jardin F, Figeac M. MicroRNAs in lymphoma, from diagnosis to targeted therapy. Curr Opin Oncol. 2013;25(5):480-486. doi:10.1097/CCO.0b013e328363def2

16. Di Lisio L, Martinez N, Montes-Moreno S, Piris-Villaespesa M, Sanchez-Beato M, Piris MA. The role of miRNAs in the pathogenesis and diagnosis of B-cell lymphomas. Blood. 2012;120 (9):1782-1790. doi:10.1182/blood-2012-05-402784

17. Malumbres R, Sarosiek KA, Cubedo E, et al. Differentiation stage-specific expression of microRNAs in B lymphocytes and diffuse large B-cell lymphomas. Blood. 2009;113(16):3754-3764. doi:10.1182/blood-2008-10-184077

18. Hershkovitzrokah O, Geva P, Salmondivon M, Shpilberg O, Libermanaronov S. Network analysis of microRNAs, genes and their regulation in diffuse and follicular B-cell lymphomas. Oncotarget. 2018;9(8):7928-7941. doi:10.18632/oncotarget. 23974

19. Lim EL, Trinh DL, Scott DW, et al. Comprehensive miRNA sequence analysis reveals survival differences in diffuse large B-cell lymphoma patients. Genome Biol. 2015;16(1):18. doi:10.1186/s13059-014-0568-y

20. Zhong $\mathrm{H}, \mathrm{Xu} \mathrm{L}$, Zhong JH, et al. Clinical and prognostic significance of miR-155 and miR-146a expression levels in formalin-fixed/paraffin-embedded tissue of patients with diffuse large B-cell lymphoma. Exp Ther Med. 2012;3(5):763-770. doi:10.3892/etm.2012.502

21. Sun JR, Zhang X, Zhang Y. MiR-214 prevents the progression of diffuse large B-cell lymphoma by targeting PD-L1. Cell Mol Biol Lett. 2019;24:68. doi:10.1186/s11658-019-0190-9

22. Bedewy AML, Elmaghraby SM, Shehata AA, Kandil NS. Prognostic value of miRNA-155 expression in B-cell non-Hodgkin lymphoma. Turk J Haematol. 2017;34(3):207-212. doi:10.4274/tjh.2016.0286 
23. Go H, Jang JY, Kim PJ, et al. MicroRNA-21 plays an oncogenic role by targeting FOXO1 and activating the PI3K/AKT pathway in diffuse large B-cell lymphoma. Oncotarget. 2015;6 (17):15035-15049. doi:10.18632/oncotarget.3729

24. Iqbal J, Shen Y, Huang X, et al. Global microRNA expression profiling uncovers molecular markers for classification and prognosis in aggressive B-cell lymphoma. Blood. 2015;125 (7):1137-1145. doi:10.1182/blood-2014-04-566778

25. Zhu FQ, Zeng L, Tang N, et al. MicroRNA-155 downregulation promotes cell cycle arrest and apoptosis in diffuse large B-cell lymphoma. Oncol Res. 2016;24(6):415-427. doi:10.3727/ 096504016X14685034103473

26. Carig VJ, Tzankov A, Flori M, Schmid CA, Bader AG, Müller A. Systemic microRNA-34a delivery induces apoptosis and abrogates growth of diffuse large B-cell lymphoma in vivo. Leukemia. 2012;26(11):2421-2424. doi:10.1038/leu.2012.110

27. Li XD, Li XM, Gu JW, Sun XC. MiR-155 regulates lymphoma cell proliferation and apoptosis through targeting SOCS3/JAK-STAT3 signaling pathway. Eur Rev Med Pharmacol Sci. 2017;21(22):5153-5159. doi:10.26355/ eurrev_201711_13832

28. Huang X, Shen Y, Liu M, et al. Quantitative proteomics reveals that miR-155 regulates the PI3K-AKT pathway in diffuse large B-cell lymphoma. Am J Pathol. 2012;181(1):26-33. doi:10.1016/ j.ajpath.2012.03.013

29. Pedersen IM, Otero D, Kao E, et al. Onco-miR-155 targets SHIP1 to promote TNFalpha-dependent growth of B cell lymphomas. EMBO Mol Med. 2009;1(5):288-295. doi:10.1002/emmm.2009 00028

30. Jiang D, Aguiar RC. MicroRNA-155 controls RB phosphorylation in normal and malignant $\mathrm{B}$ lymphocytes via the noncanonical TGF-31/SMAD5 signaling module. Blood. 2014;123(1):86-93. doi:10.1182/blood-2013-07-515254

31. Huskova H, Korecka K, Karban J, et al. Oncogenic microRNA-155 and its target PU.1: an integrative gene expression study in six of the most prevalent lymphomas. Int J Hematol. 2015;102(4):441-450. doi:10.1007/s12185-015$1847-4$

32. Due H, Schönherz AA, Ryø L, et al. MicroRNA-155 controls vincristine sensitivity and predicts superior clinical outcome in diffuse large B-cell lymphoma. Blood Adv. 2019;3(7):1185-1196. doi:10.1182/bloodadvances.2018029660

33. Liu K, Du J, Ruan L. MicroRNA-21 regulates the viability and apoptosis of diffuse large B-cell lymphoma cells by upregulating B cell lymphoma-2. Exp Ther Med. 2017;14(5):4489-4496. doi:10.3892/etm.2017.5021

34. Song J, Shao Q, Li C, et al. Effects of microRNA-21 on apoptosis by regulating the expression of PTEN in diffuse large B-cell lymphoma. Medicine. 2017;96(39):e7952. doi:10.1097/ MD.0000000000007952

35. Kim SW, Ramasamy K, Bouamar H, Lin AP, Jiang D, Aguiar RC. MicroRNAs miR-125a and miR-125b constitutively activate the $\mathrm{NF}-\mathrm{\kappa B}$ pathway by targeting the tumor necrosis factor alphainduced protein 3 (TNFAIP3, A20). Proc Natl Acad Sci U S A. 2012;109(20):7865-7870. doi:10.1073/pnas

36. Nie K, Zhang T, Allawi H, et al. Epigenetic down-regulation of the tumor suppressor gene PRDM1/Blimp-1 in diffuse large B cell lymphomas: a potential role of the microRNA let-7. $\mathrm{Am}$ $J$ Pathol. 2010;177(3):1470-1479. doi:10.2353/ajpath.2010. 091291

37. Fan Q, Meng X, Liang H, et al. MiR-10a inhibits cell proliferation and promotes cell apoptosis by targeting BCL6 in diffuse large B-cell lymphoma. Protein Cell. 2016;7(12):899-912.

38. Huang F, Jin Y, Wei Y. MicroRNA-187 induces diffuse large B-cell lymphoma cell apoptosis via targeting BCL6. Oncol Lett. 2016;11(4):2845-2850. doi:10.3892/ol.2016.4313
39. Farina FM, Inguscio A, Kunderfranco P, Cortesi A, Elia L, Quintavalle M. MicroRNA-26a/cyclin-dependent kinase 5 axis controls proliferation, apoptosis and in vivo tumor growth of diffuse large B-cell lymphoma cell lines. Cell Death Dis. 2017;8(6):e2890. doi:10.1038/cddis.2017.291

40. Jia YJ, Liu ZB, Wang WG, et al. HDAC6 regulates microRNA-27b that suppresses proliferation, promotes apoptosis and target MET in diffuse large B-cell lymphoma. Leukemia. 2018;32(3):703-711. doi:10.1038/leu.2017.299

41. Huang Y, Zou Y, Lin L, Ma X, Zheng R. MiR-101 regulates cell proliferation and apoptosis by targeting KDM1A in diffuse large B cell lymphoma. Cancer Manag Res. 2019;11:2739-2746.

42. Song G, Song G, Ni H, et al. Deregulated expression of miR-224 and its target gene: CD59 predicts outcome of diffuse large B-cell lymphoma patients treated with R-CHOP. Curr Cancer Drug Targets. 2014;14(7):659-670. doi:10.2174/15680096146661408 18211103

43. Zhu D, Fang C, He W, Wu C, Li X, Wu J. MicroRNA-181a inhibits activated B-cell-like diffuse large B-cell lymphoma progression by repressing CARD11. J Oncol. 2019;2019:9832956. doi: $10.1155 / 2019 / 9832956$

44. Zhuang $\mathrm{H}$, Shen J, Zheng Z, Luo X, Gao R, Zhuang X. MicroRNA-146a rs2910164 polymorphism and the risk of diffuse large B cell lymphoma in the Chinese Han population. Med Oncol. 2014;31(12):306. doi:10.1007/s12032-014-0306-z

45. $\mathrm{Li} \mathrm{T}$, Niu $\mathrm{L}, \mathrm{Wu} \mathrm{L}$, et al. A functional polymorphism in microRNA-196a2 is associated with increased susceptibility to non-Hodgkin lymphoma. Tumour Biol. 2015;36(5):3279-3284. doi:10.1007/s13277-014-2957-y

46. Kwanhian W, Lenze D, Alles J, et al. MicroRNA-142 is mutated in about $20 \%$ of diffuse large B-cell lymphoma. Cancer Med. 2012;1(2):141-155. doi:10.1002/cam4.29

47. Eis PS, Tam W, Sun L, et al. Accumulation of miR-155 and BIC RNA in human B cell lymphomas. Proc Natl Acad Sci U S A. 2005;102(10):3627-3632. doi:10.1073/pnas.0500613102

48. Di Lisio L, Sánchez-Beato M, Gómez-López G, et al. MicroRNA signatures in B-cell lymphomas. Blood Cancer J. 2012;2(2):e57. doi:10.1038/bcj.2012.1

49. Lenze D, Leoncini L, Hummel M, et al. The different epidemiologic subtypes of Burkitt lymphoma share a homogenous microRNA profile distinct from diffuse large B-cell lymphoma. Leukemia. 2011;25:1869-1876. doi:10.1038/leu.2011.156

50. Gebauer N, Thorns C, Bernard V, et al. MicroRNA profiling of low-grade and transformed nodal marginal zone lymphoma reveals a similar signature pattern distinct from diffuse large B cell lymphoma. Acta Haematol. 2015;133(2):214-220. doi:10.1159/000363096

51. Roehle A, Hoefig KP, Repsilber D, et al. MicroRNA signatures characterize diffuse large B-cell lymphomas and follicular lymphomas. Br J Haematol. 2008;142(5):732-744. doi:10.1111/ j.1365-2141.2008.07237.x

52. Culpin RE, Proctor SJ, Angus B, Crosier S, Anderson JJ, MainouFowler T. A 9 series microRNA signature differentiates between germinal centre and activated B-cell-like diffuse large B-cell lymphoma cell lines. Int $J$ Oncol. 2010;37(2):367-376. doi:10.3892/ijo_00000685

53. Fassina A, Marino F, Siri M, et al. The miR-17-92 microRNA cluster: a novel diagnostic tool in large B-cell malignancies. Lab Invest. 2012;92(11):1574-1582. doi:10.1038/labinvest.2012.129

54. Tamaddon G, Geramizadeh B, Karimi MH, Mowla SJ, Abroun S. MiR-4284 and miR-4484 as putative biomarkers for diffuse large B-cell lymphoma. Iran J Med Sci. 2016;41(4):334-339.

55. Lawrie $\mathrm{CH}$, Soneji $\mathrm{S}$, Marafioti $\mathrm{T}$, et al. MicroRNA expression distinguishes between germinal center B cell-like and activated B cell-like subtypes of diffuse large B cell lymphoma. Int J Cancer. 2007;121(5):1156-1161. doi:10.1002/ijc.22800 
56. Montes-Moreno S, Martinez N, Sanchez-Espiridión B, et al. MiRNA expression in diffuse large B-cell lymphoma treated with chemoimmunotherapy. Blood. 2011;118(4):1034-1040. doi:10.1182/blood-2010-11-321554

57. Rai D, Karanti S, Jung I, Dahia PL, Aguiar RC. Coordinated expression of microRNA-155 and predicted target genes in diffuse large B-cell lymphoma. Cancer Genet Cytogenet. 2008;181 (1):8-15. doi:10.1016/j.cancergencyto.2007.10.008

58. Wu PY, Zhang XD, Zhu J, Guo XY, Wang JF. Low expression of microRNA-146b-5p and microRNA-320d predicts poor outcome of large B-cell lymphoma treated with cyclophosphamide, doxorubicin, vincristine, and prednisone. Hum Pathol. 2014;45 (8):1664-1673. doi:10.1016/j.humpath.2014.04.002

59. Clausen MR, Maurer MJ, Ulrichsen SP, et al. Pretreatment hemoglobin adds prognostic information to the NCCN-IPI in patients with diffuse large B-cell lymphoma treated with anthracycline-containing chemotherapy. Clin Epidemiol. 2019;11:987-996. doi:10.2147/CLEP.S219595

60. Wu X, Wang F, Li Y, et al. Evaluation of latent membrane protein 1 and microRNA-155 for the prognostic prediction of diffuse large B cell lymphoma. Oncol Lett. 2018;15(6):9725-9734. doi:10.3892/ol.2018.8560

61. Berglund M, Hedström G, Amini RM, Enblad G, Thunberg U. High expression of microRNA-200c predicts poor clinical outcome in diffuse large B-cell lymphoma. Oncol Rep. 2013;29 (2):720-724. doi:10.3892/or.2012.2173

62. Alencar AJ, Malumbres R, Kozloski GA, et al. MicroRNAs are independent predictors of outcome in diffuse large B-cell lymphoma patients treated with R-CHOP. Clin Cancer Res. 2011;17 (12):4125-4135. doi:10.1158/1078-0432.CCR-11-0224

63. Ni H, Wang X, Liu H, Tian F, Song G. Low expression of miRNA-224 predicts poor clinical outcome in diffuse large B-cell lymphoma treated with R-CHOP. Biomarkers. 2015;20 (4):253-257. doi:10.3109/1354750X.2015.1068855

64. Marques SC, Ranjbar B, Laursen MB, et al. High miR-34a expression improves response to doxorubicin in diffuse large B-cell lymphoma. Exp Hematol. 2016;44(4):238-246. doi:10.1016/j.exphem.2015.12.007

65. Yang JM, Jang JY, Jeon YK, Paik JH. Clinicopathologic implication of microRNA-197 in diffuse large B cell lymphoma. $J$ Transl Med. 2018;16(1):162. doi:10.1186/s12967-018-1537-0

66. Troppan K, Wenzl K, Pichler M, et al. MiR-199a and miR-497 are associated with better overall survival due to increased chemosensitivity in diffuse large B-Cell lymphoma patients. Int $J$ Mol Sci. 2015;16(8):18077-18095. doi:10.3390/ijms16 0818077

67. Bai H, Wei J, Deng C, Yang X, Wang C, Xu R. MicroRNA-21 regulates the sensitivity of diffuse large B-cell lymphoma cells to the CHOP chemotherapy regimen. Int J Hematol. 2013;97 (2):223-231. doi:10.1007/s12185-012-1256-x

68. Zhang Y, Guo CC, Guan DH, Yang CH, Jiang YH. Prognostic value of microRNA-224 in various cancers: a meta-analysis. Arch Med Res. 2017;48(5):472-482. doi:10.1016/j.arcmed.2017.11.002

69. Leivonen SK, Icay K, Jäntti K, et al. MicroRNAs regulate key cell survival pathways and mediate chemosensitivity during progression of diffuse large B-cell lymphoma. Blood Cancer J. 2017;7(12):654. doi:10.1038/s41408-017-0033-8

70. Kim J, Jeong D, Nam J, et al. MicroRNA-124 regulates glucocorticoid sensitivity by targeting phosphodiesterase $4 \mathrm{~B}$ in diffuse large B cell lymphoma. Gene. 2015;558(1):173-180. doi:10.1016/ j.gene.2015.01.001

71. Yuan WX, Gui YX, Na WN, Chao J, Yang X. Circulating microRNA-125b and microRNA-130a expression profiles predict chemoresistance to R-CHOP in diffuse large B-cell lymphoma patients. Oncol Lett. 2016;11(1):423-432. doi:10.3892/ ol.2015.3866
72. Sun N, Wang CY, Sun YQ, et al. Down-regulated miR-148b increases resistance to CHOP in diffuse large B-cell lymphoma cells by rescuing Ezrin. Biomed Pharmacother. 2018;106:267-274. doi:10.1016/j.biopha.2018.06.093

73. Feng Y, Zhong M, Zeng S, et al. Exosome-derived miRNAs as predictive biomarkers for diffuse large B-cell lymphoma chemotherapy resistance. Epigenomics. 2019;11(1):35-51. doi:10.2217/epi-2018-0123

74. Imig J, Motsch N, Zhu JY, et al. MicroRNA profiling in Epstein-Barr virus-associated B-cell lymphoma. Nucleic Acids Res. 2011;39(5):1880-1893. doi:10.1093/nar/gkq1043

75. Rahadiani N, Takakuwa T, Tresnasari K, Morii E, Aozasa K. Latent membrane protein-1 of Epstein-Barr virus induces the expression of B-cell integration cluster, a precursor form of microRNA-155, in B lymphoma cell lines. Biochem Biophys Res Commun. 2008;377 (2):579-583. doi:10.1016/j.bbrc.2008.10.007

76. Wood CD, Carvell T, Gunnell A, Ojeniyi OO, Osborne C, West MJ. Enhancer control of microRNA miR-155 expression in Epstein-Barr virus-infected B cells. $J$ Virol. 2018;92(19): e00716-e00718. doi:10.1128/JVI.00716-18

77. Zheng Z, Sun R, Zhao HJ, et al. MiR155 sensitized B-lymphoma cells to anti-PD-L1 antibody via PD-1/PD-L1-mediated lymphoma cell interaction with CD8+ T cells. Mol Cancer. 2019;18 (1):54. doi:10.1186/s12943-019-0977-3

78. Andrade TA, Evangelista AF, Campos AH, et al. A microRNA signature profile in EBV+ diffuse large B-cell lymphoma of the elderly. Oncotarget. 2014;5(23):11813-11826. doi:10.18632/ oncotarget. 2952

79. Re A, Cattaneo C, Rossi G. Hiv and lymphoma: from epidemiology to clinical management. Mediterr J Hematol Infect Dis. 2019;11(1):e2019004. doi:10.4084/MJHID.2019.004

80. Thapa DR, Li X, Jamieson BD, Martínez-Maza O. Overexpression of microRNAs from the miR-17-92 paralog clusters in AIDS-related non-Hodgkin's lymphomas. PLoS One. 2011;6(6):e20781. doi:10.1371/journal.pone.0020781

81. Thapa DR, Hussain SK, Tran WC, et al. Serum microRNAs in HIV-infected individuals as pre-diagnosis biomarkers for AIDS-NHL. J Acquir Immune Defic Syndr. 2014;66(2):229-237. doi:10.1097/QAI.0000000000000146

82. Vannata B, Arcaini L, Zucca E. Hepatitis C virus-associated B-cell non-Hodgkin's lymphomas: what do we know? Ther $A d v$ Hematol. 2016;7(2):94-107. doi:10.1177/2040620715623924

83. Augello C, Gianelli U, Savi F, et al. MicroRNA as potential biomarker in HCV-associated diffuse large B-cell lymphoma. $J$ Clin Pathol. 2014;67(8):697-701. doi:10.1136/jclinpath-2014-202352

84. Lasda E, Parker R. Circular RNAs: diversity of form and function. RNA. 2014;20(12):1829-1842. doi:10.1261/rna.047126.114

85. Wang F, Nazarali AJ, Circular JS. RNAs as potential biomarkers for cancer diagnosis and therapy. Am J Cancer Res. 2016;6 (6):1167-1176.

86. Jeck WR, Sorrentino JA, Wang K, et al. Circular RNAs are abundant, conserved, and associated with ALU repeats. RNA. 2013;19(2):141-157. doi:10.1261/rna.035667.112

87. Memczak S, Jens M, Elefsinioti A, et al. Circular RNAs are a large class of animal RNAs with regulatory potency. Nature. 2013;495(7441):333-338. doi:10.1038/nature11928

88. Suzuki H, Tsukahara T. A view of pre-mRNA splicing from RNase R resistant RNAs. Int J Mol Sci. 2014;15(6):9331-9342. doi:10.3390/ijms 15069331

89. Danan M, Schwartz S, Edelheit S, Sorek R. Transcriptome-wide discovery of circular RNAs in Archaea. Nucleic Acids Res. 2011;40:3131-3142. doi:10.1093/nar/gkr1009

90. Nicolet BP, Engels S, Aglialoro F, van den Akker E, von Lindern M, Wolkers MC. Circular RNA expression in human hematopoietic cells is widespread and cell-type specific. Nucleic Acids Res. 2018;46(16):8168-8180. doi:10.1093/nar/gky721 
91. Hu Y, Zhao Y, Shi C, et al. A circular RNA from APC inhibits the proliferation of diffuse large B-cell lymphoma by inactivating Wnt/ $\beta$-catenin signaling via interacting with TET1 and miR-888. Aging. 2019;11(19):8068-8084. doi:10.18632/ aging. 102122

92. Zhong $\mathrm{Y}$, Du $\mathrm{Y}$, Yang $\mathrm{X}$, et al. Circular RNAs function as ceRNAs to regulate and control human cancer progression. $\mathrm{Mol}$ Cancer. 2018;17(1):79. doi:10.1186/s12943-018-0827-8

93. Kristensen LS, Hansen TB, Venø MT, Kjems J. Circular RNAs in cancer: opportunities and challenges in the field. Oncogene. 2018;37:555-565. doi:10.1038/onc.2017.361

94. Geng Y, Jiang J, Wu C. Function and clinical significance of circRNAs in solid tumors. J Hematol Oncol. 2018;11(1):98. doi:10.1186/s13045-018-0643-z

95. Jahani S, Nazeri E, Majidzadeh-A K, Jahani M, Esmaeili R. Circular RNA; a new biomarker for breast cancer: A systematic review. J Cell Physiol. 2020;235(7-8):5501-5510. doi:10.1002/ jcp. 29558

96. Zhang C, Ma L, Niu Y, et al. Circular RNA in lung cancer research: biogenesis, functions, and roles. Int $J$ Biol Sci. 2020;16(5):803-814. doi:10.7150/ijbs.39212

97. Hao S, Cong L, Qu R, Liu R, Zhang G, Li Y. Emerging roles of circular RNAs in colorectal cancer. Onco Targets Ther. 2019;12:4765-4777. doi:10.2147/OTT.S208235

98. Dahl M, Daugaard I, Andersen MS, et al. Enzyme-free digital counting of endogenous circular RNA molecules in B-cell malignancies. Lab Invest. 2018;98(12):1657-1669. doi:10.1038/ s41374-018-0108-6

99. Caley DP, Pink RC, Trujillano D, Carter DR. Long noncoding RNAs, chromatin, and development. Sci World J. 2010;10:90-102. doi:10.1100/tsw.2010.7

100. Fatima R, Akhade VS, Pal D, Rao SM. Long noncoding RNAs in development and cancer: potential biomarkers and therapeutic targets. Mol Cell Ther. 2015;3:5. doi:10.1186/s40591-015-00426

101. Wang FY, Gu ZY, Gao CJ. Emerging role of long non-coding RNAs in normal and malignant hematopoiesis. Chin Med J. 2020;133(4):462-473. doi:10.1097/CM9.0000000000000624

102. Tayari MM, Winkle M, Kortman G, et al. Long noncoding RNA expression profiling in normal B-cell subsets and hodgkin lymphoma reveals Hodgkin and Reed-Sternberg cell-specific long noncoding RNAs. Am J Pathol. 2016;186(9):2462-2472. doi:10.1016/j.ajpath.2016.05.011

103. Verma A, Jiang Y, Du W, Fairchild L, Melnick A, Elemento O. Transcriptome sequencing reveals thousands of novel long non-coding RNAs in B cell lymphoma. Genome Med. 2015;7:110. doi:10.1186/s13073-015-0230-7

104. Gao HY, Wu B, Yan W, et al. Microarray expression profiles of long non-coding RNAs in germinal center-like diffuse large B-cell lymphoma. Oncol Rep. 2017;38(3):1363-1372. doi:10.3892/or.2017.5821

105. Zhu D, Fang C, Li X, et al. Predictive analysis of longnon-coding RNA expression profifiles in diffuse large B cell lymphoma. Oncotarget. 2017;8(14):23228-23236. doi:10.18632/ oncotarget.15571

106. Dousti F, Shahrisa A, Ansari H, et al. Long non-coding RNAs expression levels in diffuse large B-cell lymphoma: an in silico analysis. Pathol Res Pract. 2018;214(9):1462-1466. doi:10.1016/ j.prp.2018.08.006

107. Fatica A, Bozzoni I. Long non-coding RNAs: new players in cell differentiation and development. Nat Rev Genet. 2014;15 (1):7-21. doi:10.1038/nrg3606

108. Wang QM, Lian GY, Song Y, Huang YF, Gong Y. LncRNA MALAT1 promotes tumorigenesis and immune escape of diffuse large B cell lymphoma by sponging miR-195. Life Sci. 2019;231:116335. doi:10.1016/j.1fs.2019.03.040
109. Zhao L, Liu Y, Zhang J, Liu Y, Qi Q. LncRNA SNHG14/ miR-5590-3p/ZEB1 positive feedback loop promoted diffuse large B cell lymphoma progression and immune evasion through regulating PD-1/PD-L1 checkpoint. Cell Death Dis. 2019;10 (10):731. doi:10.1038/s41419-019-1886-5

110. Zhu Q, Li Y, Guo Y, et al. Long non-coding RNA SNHG16 promotes proliferation and inhibits apoptosis of diffuse large B-cell lymphoma cells by targeting miR-497-5p/PIM1 axis. J Cell Mol Med. 2019;23(11):7395-7405. doi:10.1111/ jcmm.14601

111. Chen LY, Zhang XM, Han BQ, Dai HB. Long noncoding RNA SNHG12 indicates the prognosis and accelerates tumorigenesis of diffuse large B-Cell lymphoma through sponging microR-195. Onco Targets Ther. 2020;13:5563-5574. doi:10.2147/OTT. S249429

112. Deng L, Jiang L, Tseng KF, et al. Aberrant NEAT1_1 expression may be a predictive marker of poor prognosis in diffuse large B cell lymphoma. Cancer Biomark. 2018;23(2):157-164. doi:10.3233/CBM-160221

113. Peng W, Feng J. Long noncoding RNA LUNAR1 associates with cell proliferation and predicts a poor prognosis in diffuse large B-cell lymphoma. Biomed Pharmacother. 2016;77:65-71. doi:10.1016/j.biopha.2015.12.001

114. Peng $\mathrm{W}, \mathrm{Wu}$ J, Feng J. Long noncoding RNA HULC predicts poor clinical outcome and represents pro-oncogenic activity in diffuse large B-cell lymphoma. Biomed Pharmacother. 2016;79:188-193. doi:10.1016/j.biopha.2016.02.032

115. Peng W, Wu J, Feng J. LincRNA-p21 predicts favorable clinical outcome and impairs tumorigenesis in diffuse large B cell lymphoma patients treated with R-CHOP chemotherapy. Clin Exp Med. 2017;17(1):1-8. doi:10.1007/s10238-015-0396-8

116. Wang $\mathrm{Y}$, Zhang $\mathrm{M}, \mathrm{Xu} \mathrm{H}$, et al. Discovery and validation of the tumor-suppressive function of long noncoding RNA PANDA in human diffuse large B-cell lymphoma through the inactivation of MAPK/ERK signaling pathway. Oncotarget. 2017;8 (42):72182-72196. doi:10.18632/oncotarget.20053

117. Yan Y, Han J, Li Z, Yang H, Sui Y, Wang M. Elevated RNA expression of long non-coding HOTAIR promotes cell proliferation and predicts a poor prognosis in patients with diffuse large B cell lymphoma. Mol Med Rep. 2016;13(6):5125-5131. doi:10.3892/mmr.2016.5190

118. Zhao CC, Jiao Y, Zhang YY, et al. Lnc SMAD5-AS1 as ceRNA inhibit proliferation of diffuse large B cell lymphoma via Wnt/ $\beta$ catenin pathway by sponging miR-135b-5p to elevate expression of APC. Cell Death Dis. 2019;10(4):252. doi:10.1038/s41419019-1479-3

119. Shi X, Cui Z, Liu X, et al. LncRNA FIRRE is activated by MYC and promotes the development of diffuse large B-cell lymphoma via Wnt/ $\beta$-catenin signaling pathway. Biochem Biophys Res Commun. 2019;510(4):594-600. doi:10.1016/j. bbrc.2019.01.105

120. Meng H, Zhao B, Wang Y. FOXM1-induced upregulation of lncRNA OR3A4 promotes the progression of diffuse large B-cell lymphoma via Wnt/ $\beta$-catenin signaling pathway. Exp Mol Pathol. 2020;115:104451. doi:10.1016/j. yexmp.2020.104451

121. Peng W, Fan H, Wu G, Wu J, Feng J. Upregulation of long noncoding RNA PEG10 associates with poor prognosis in diffuse large B cell lymphoma with facilitating tumorigenicity. Clin Exp Med. 2016;16(2):177-182. doi:10.1007/s10238-015-0350-9

122. Zhou M, Zhao H, Xu W, Bao S, Cheng L, Sun J. Discovery and validation of immune-associated long non-coding RNA biomarkers associated with clinically molecular subtype and prognosis in diffuse large B cell lymphoma. Mol Cancer. 2017;16(1):16. doi:10.1186/s12943-017-0580-4 
123. Zhao S, Fang S, Liu Y, et al. The long non-coding RNA NONHSAG026900 predicts prognosis as a favorable biomarker in patients with diffuse large B-cell lymphoma. Oncotarget. 2017;8(21):34374-34386. doi:10.18632/oncotarget.16163
124. Sun J, Cheng L, Shi H, et al. A potential panel of six-long non-coding RNA signature to improve survival prediction of diffuse large-B-cell lymphoma. Sci Rep. 2016;6:27842. doi: $10.1038 /$ srep 27842

\section{Publish your work in this journal}

OncoTargets and Therapy is an international, peer-reviewed, open access journal focusing on the pathological basis of all cancers, potential targets for therapy and treatment protocols employed to improve the management of cancer patients. The journal also focuses on the impact of management programs and new therapeutic

Submit your manuscript here: https://www.dovepress.com/oncotargets-and-therapy-journal agents and protocols on patient perspectives such as quality of life, adherence and satisfaction. The manuscript management system is completely online and includes a very quick and fair peer-review system, which is all easy to use. Visit http://www.dovepress.com/ testimonials.php to read real quotes from published authors. 